\title{
MULTIDISCIPLINARY APPROACH TO LINEAR AEROSPIKE NOZZLE OPTIMIZATION
}

\author{
J. J. Korte*, A.O. Salas $\ddagger$, H.J. Dunn ${ }^{\dagger}$, and N.M. Alexandrov $\ddagger$ \\ NASA Langley Research Center, Hampton, Virginia 23681 \\ and \\ W.W. Follett ${ }^{\S}$, G. E. Orient ${ }^{\S}$, and A.H. Hadid ${ }^{\S}$ \\ Rocketdyne Division of Boeing North American, Canoga Park, CA 91309
}

\begin{abstract}
A model of a linear aerospike rocket nozzle that consists of coupled aerodynamic and structural analyses has been developed. A nonlinear computational fluid dynamics code is used to calculate the aerodynamic thrust, and a three-dimensional finite-element model is used to determine the structural response and weight. The model will be used to demonstrate multidisciplinary design optimization (MDO) capabilities for relevant engine concepts, assess performance of various MDO approaches, and provide a guide for future application development. In this study, the MDO problem is formulated using the multidisciplinary feasible (MDF) strategy. The results for the MDF formulation are presented with comparisons against sequential aerodynamic and structural optimized designs. Significant improvements are demonstrated by using a multidisciplinary approach in comparison with the singlediscipline design strategy.
\end{abstract}

\section{Introduction}

A multidisciplinary analytic model of a linear aerospike rocket nozzle has been developed; this model includes predictions of nozzle thrust, nozzle weight, and effectivevehicle gross-liftoff weight (GLOW). The linear aerospike rocket engine is the propulsion system proposed for the X-33 and the VentureStar ${ }^{1}$ (Fig. 1) reusable launch vehicle (RLV). The model has been developed to demonstrate multidisciplinary design optimization (MDO) capabilities for relevant engine concepts, assess performance of various MDO approaches, and provide a guide for future application development. The MDO approach is a methodology for the design of complex engineering systems and subsystems that coherently exploits the synergism of mutually interacting phenomena. ${ }^{2}$ Traditional methods of design, analysis, and optimization have been based on the approach where disciplines are isolated. This work has focused on developing and implementing a baseline MDO problem using the multidisciplinary feasible (MDF) strategy. ${ }^{3}$ This paper presents the results for singlediscipline and multidisciplinarily optimized aerospike rocket nozzle designs.

The aerospike rocket engine consists of a rocket thruster, cowl, aerospike nozzle, and plug base region
(Fig. 2). The aerospike nozzle is a truncated spike (or plug nozzle) that adjusts to the ambient pressure ${ }^{4}$ and potentially integrates well with launch vehicles. The flow-field structure changes dramatically from low altitude to high altitude on the spike surface and in the base region. ${ }^{5-7}$ Additional flow bleeds into the base region to create an aerodynamic spike $^{8}$ (giving the aerospike its name), which increases the base pressure, and the contribution of the base region to the aerospike thrust. In the early 1960 's, aerospike and plug nozzles were the focus of development projects in the United States, ${ }^{8}$ Italy, ${ }^{9}$ and Germany. ${ }^{10}$ More recently, they have been proposed as the propulsion system for the RLV program for NASA ${ }^{11}$ and studied in the Advanced Rocket Propulsion Technologies ${ }^{12}$ and Future European Space Transportation Investigations Programme ${ }^{13}$ for ESA. This effort is focused on using preliminary design level analysis methods in a multidisciplinary approach to aerospike nozzle design.

The contour of the aerospike nozzle has been traditionally designed by using both simple methods ${ }^{14,15}$ and more elaborate methods based on calculus of variations. ${ }^{16-18}$ These design approaches are adequate for determining an aerodynamic contour that approximates or exactly satisfies a design for maximum thrust at one design condition (usually vacuum). However, the nozzle contour is usually modified as the design of the engine progresses. For example, the length of the nozzle may be varied to improve the thrust-to-weight ratio of the engine. In addition to structural weight effects, the thermal cooling system, propulsion-vehicle integration, thruster contour design, ${ }^{19}$ and the fuel-oxidizer delivery system are a few of the topics that are significant in the aerospike nozzle design.

Rocketdyne and NASA Langley Research Center have formed cooperative research teams as part of a Space Act Agreement that initially focuses on multidisciplinary techniques for preliminary design of an aerospike nozzle. In our approach, computational fluid dynamics (CFD) and finite-element (FE) codes are used to compute the thrust and the weight, respectively (Fig. 3). Mission-averaged engine-specific thrust and thrustto-weight ratio are computed and used to determine GLOW from vehicle-based algorithms. The aerospike geometry (length, base height, and surface contour) and the structural (thickness, I-beam dimensions, tube radii)

\footnotetext{
* Senior Research Engineer, Mail Stop 159, Multidisciplinary Optimization Branch, Senior Member AIAA. $\dagger$ Aerospace Engineer, Mail Stop 159, Multidisciplinary Optimization Branch. $\ddagger$ Research Scientist, Mail Stop 159, Multidisciplinary Optimization Branch. 
design parameters are computed to satisfy structural constraints (displacements, stress, and buckling). An MDF formulation has been implemented to obtain a baseline MDO design for comparison with future MDO formulations. An aerospike design problem has been formulated with a goal of minimizing GLOW. Multidisciplinary synergy has been demonstrated for the optimized design by demonstrating improved performance compared with the more traditional singlediscipline design strategy.

The paper is organized in the following manner. In section 2 , we first describe the aerodynamic and structural analysis models, along with their corresponding design variables and responses. Subsequently, the multidisciplinary objective function and system responses are discussed. Also, a discussion of the MDF strategy and alternative formulations is included. Results for both optimized designs from single and multidisciplinary problems are presented in section 3 . Finally, a summary of this initial work is provided.

\section{Multidisciplinary Problem Development}

For this initial effort, we have concentrated on the development of a multidisciplinary analysis. The analysis includes the use of a nonlinear CFD code and an FE code to calculate aerodynamic thrust and structural weight. In this section, the discipline problems and their corresponding design parameters are presented, along with the discipline analyses related to the objective function. Next, a baseline MDO methodology for the aerospike nozzle design is defined. The design problem that has been considered is representative of an early preliminary engine design process; we have assumed that a conceptual vehicle design study has been completed that selected a linear aerospike rocket engine as the propulsion system.

\section{Aerospike Nozzle Geometry Parameters}

The aerospike nozzle geometry is treated as a twodimensional surface defined from a fixed point at the end of the cowl $\left(y_{\text {cowl }}\right)$. The slope of the first point on the aerospike nozzle is set equal to the tangent of the thruster angle. The nozzle surface shape is defined with three spline knots. The thruster exit height is held constant, and the initial nozzle contour point is located in the same axial location as the end of the cowl. The important geometry parameters for an aerospike nozzle are the thruster angle, nozzle surface shape (defined by a cubic spline), nozzle length, and base height (Fig. 4).

\section{Aerodynamic Analysis}

Aerodynamic analysis is used to determine data necessary for computing the engine thrust and the static loading on the nozzle structure. The aerodynamic analysis is computed in three parts: the flow out of the thruster up to the start of the nozzle (one-dimensional analysis), expansion of the flow on the aerospike nozzle (two-dimensional nonlinear CFD), and the base thrust (phenomenological model). This approach is efficient and allows direct comparison with existing preliminary aerodynamic analysis and design methods based on the traditional method of characteristics (MOC).

The one-dimensional equation for the rocket thruster thrust is given by

$$
\begin{aligned}
\text { thrust }_{1} & =p A\left(1+\gamma M^{2}\right) \cos \left(\text { thr } r_{\text {angle }}\right) \\
& +p A\left(1 / \cos \left(\text { thr } r_{\text {angle }}\right)-\cos \left(\left(t h r_{\text {angle }}\right)\right)\right.
\end{aligned}
$$

where $p, A, M, \gamma$, and $t h r_{\text {angle }}$ are static pressure, crosssectional area, Mach number, ratio of specific heats, and thruster angle (with respect to the horizontal axis). Note that the data are evaluated at the exit plane of the thruster. The last term in the equation quantifies the thrust contribution from the nozzle wall contour between the thruster exit and the end of the cowl. Downstream of the cowl, the thrust from the nozzle wall contour is calculated by integrating the nozzle wall pressure over the surface area projected in the axial direction. The base thrust is calculated by multiplying the base pressure by the corresponding base area.

The pressure distribution on the nozzle contour is calculated using a space marching parabolized NavierStokes code..$^{20}$ The computational domain begins at a vertical plane at the cowl and ends at the nozzle exit. The domain is bounded by the nozzle wall on the bottom and the flow expansion on the top. The combustion products are assumed to be water and to be in vibrational equilibrium. The flow that exits the thruster onto the nozzle is assumed to be spatially uniform. The computed flow field is equivalent to an Euler flow-field solution because the boundary condition imposed was a slip wall condition. The computational grid uses 60 points in the normal direction and approximately 2000 streamwise stations. The nozzle thrust calculation was validated by comparing the solution with an MOC flow solution and performing a grid convergence study. The nozzle thrust calculation takes approximately $15 \mathrm{sec}$ on a SUN Sparc Ultra II workstation and differs from the MOC solution by less than 0.08 percent, and from the grid-converged solution by less than 0.1 percent.

The wall pressure, Mach number, and flow angle at the end of the nozzle are parameters required to analyze the base pressure. The base pressure is computed by using a phenomenological model developed by both Chapman $^{21}$ and Korst $^{22}$ (for predicting supersonic base flow pressures). An accurate CFD calculation or model for predicting base-flow pressures is extremely difficult to develop. This model is believed to be a conservative estimate of the base pressure and is typical of the level of detail used in a preliminary design.

\section{FE Model and Structure Design Parameters}

The structural design concept was generated explicitly for this study and does not relate to a structural configuration that has previously been designed or studied for an aerospike nozzle design. The model represents a typical structural problem that is encountered in the design process. An FE model (FEM) is generated based on the geometric (Fig. 4) and structural (Fig. 5) design variables. The FEM is a thrust module and begins at the cowl and ends at the base plate. The model is 
defined by using 41 structural-design parameters and additional geometry-design variables. The model has an outer "hot" wall and an inner "cold" wall which define top and bottom surfaces of the structural box. The nozzle module is defined using 10 boxes in the longitudinal direction and 4 in the spanwise direction. The sides of the boxes are thin plates (axial and longitudinal webs) with shell stiffeners in the corners of the boxes. The box structure is supported by an I-beam that is attached to the cold wall on one side of the thruster module. The web height and flange thickness, in the vertical direction, of the I-beam are independent parameters for each box. Six support truss members are connected to the I-beam, where each support member is defined by an inner radius and a wall thickness. The FEM is fixed at the attachment point of the cold wall to the thruster. The support truss members are free to move in-plane; their lower ends remain on the nozzle centerline. The yield strength of the outer "hot" wall is reduced to account for the temperature dependency of the material properties.

Two FEM codes have been used with different approaches for building the FEM as a function of the geometric and structural design parameters. The first approach used the ANSYS FE code and defined a parametric FEM by using the ANSYS parametric-design language. ${ }^{23}$ The second approach used NASTRAN ${ }^{24}$ for the $\mathrm{FE}$ analysis and a code written with MATLAB ${ }^{25}$ to generate the NASTRAN input as a function of the parametric inputs. Each approach was used successfully, and reasonable agreement between the two analyses was obtained for this sample problem.

The FE solution was obtained for both static and buckling analyses. The FE analysis calculates the weight of the nozzle module. The stresses and resulting displacements from the static analysis are used to partially define the structural constraints, and the buckling analysis is used to calculate the remaining constraints.

\section{GLOW Determination}

The objective of most vehicle designs is the minimization of the vehicle weight (either empty or full of fuel). While this process is normally done when the vehicle is designed, the process is difficult to include in the development of subsystems designs. In this approach, an attempt is made to relate the subsystem design directly to the vehicle performance. Assuming that a performance map for GLOW is developed during the conceptual design, the proposed design strategy is applicable.

To determine the GLOW, the FE weight of the aerospike nozzle is added to the thruster and engine fuel delivery system weight (turbo-pumps, piping, etc.) to obtain the total engine weight. The thrust and weight predictions are then used to compute engine ISP (specific impulse assuming constant engine mass flow rate) and T/Wt (thrust-to-total-engine-weight ratio) for a near vacuum condition. A mission-average thrust value is estimated by assuming a 100-sec ISP loss at sea level and by assuming that the sea-level operation accounts for 20 percent of the mission-average thrust. The missionaverage ISP and T/Wt values are then used in a table look-up fashion to determine estimates on vehicle GLOW. The main advantage of this approach is that it allows the aerospike design parameters to be determined by an optimization problem defined based on a vehiclemission objective. Future efforts will include analyses at sea level (important for cooling) and possibly other trajectory points.

\section{MDO Methods}

Multidisciplinary optimization methods deal with techniques for solving optimization problems coupled with two or more discipline analyses and constraints. Because of the extreme complexity, problem formulations play a significant role in determining the solution technique and the efficiency of the optimization algorithm. In this investigation, various schemes for multidisciplinary optimization were investigated and are subsequently discussed, (see ref. 26 for an overview of existing approaches.)

MDF Method .

The MDF problem is the optimization of a system objective, subject to satisfying a number of disciplinary analyses and their constraints; at each iteration, a complete multidisciplinary analysis is performed. This is done by iterating between the disciplines until singlediscipline feasibility is achieved in all disciplines simultaneously. This iteration process is ordinarily a Gauss-Seidel-like procedure that transfers the output of each discipline into the input of the others, until all discipline output provides solutions to other appropriate disciplines.

We have assembled a multidisciplinary analysis module based on the MDF formulation that calls the discipline codes, transfers the appropriate input/output data between them, and then calls an optimization routine $^{27}$ (Fig. 6) for solving the aerospike nozzle problem. In our baseline case, aerodynamics and structures are weakly coupled because no feedback is given from structures to aerodynamics. This results in a single aerodynamics-to-structures solution that provides an MDF vector of design variables. In the future, when attempting MDO of the strongly coupled version of this problem, where structural displacements modify the nozzle shape, we will address the coupling in a number of ways. The promise of other MDO formulations is to eliminate the necessity of reaching the expensive multidisciplinary feasibility.

Although the MDF approach leads to small, dense optimization problems, the resulting computation is expensive and lengthy because of the necessity to perform not only full multidisciplinary analysis but also sensitivity analysis. The main advantage of the MDF approach is the use of the disciplinary expertise and software. The other important advantage is the availability of an MDF design at each iteration, which is important if the computational expense and time considerations do not allow the optimization procedure to reach completion. These factors are important from the engineering perspective because the MDF approach is the conventional approach for multidisciplinary design, and 
we can use this method to serve as a baseline case for future comparisons with computational results of other formulations.

\section{MDO Results}

In this study, we investigated two different methods of design. The first method attempts to develop a preliminary design by optimizing the disciplines sequentially. By using the optimal thrust and nozzle weight obtained, the GLOW is calculated. This first method is a model of a typical design approach. The second method utilizes the MDF formulation and minimizes the GLOW directly subject to satisfying the structural constraints. The gradient-based optimization method, CONMIN, was used in all cases. The gradients were calculated using finite differences. The optimization process was required to satisfy the minimum relative or absolute change of the objective function for three consective iterations as a convergence criteria.

The design parameters include 4 geometry variables and 14 structural variables (Table 1). The initial geometry design variables were selected from previous design studies on aerospike nozzles using conventional design methods and are expected to approximate an optimized aerodynamic shape. The number of structural design variables was reduced by mapping some of the design variables with common attributes into a single design variable. In particular, the thickness of the Ibeams was made to be the same in each structural box, and the six structural supports were required to have the same radius and wall thickness. Additional structural parameters are used in forming the constraints (Table 2). The initial values selected for the structural design parameters resulted in a structural design that was infeasible.

\section{Method I--Current Design and Optimization Practice}

A nozzle geometry design optimized for maximum thrust at the baseline length is presented. Additionally, designs with nozzle lengths of \pm 10 percent of the baseline length have also been computed and yield similar results. Four geometry variables were used to determine a nozzle contour for maximum thrust. The convergence of thrust during the optimization is shown in Fig. 7.

The wall pressure distribution and geometry for the maximized thrust design was input to the structural design optimization. Fourteen structural design variables were varied to minimize the weight of the aerospike nozzle module. The convergence sequence of the nozzle weight is shown in Fig. 8. Note that the nozzle weight at first increases, while the optimization strategy adjusts the design for structural feasibility.

\section{Method II--MDF Approach}

The MDF results are plotted nondimensionalized by the single-discipline final optimization result. Method II uses the results of Method $I$ as the initial values of the design variables. The GLOW is minimized for the multidisciplinary design at the baseline length. The improvement in the GLOW for the aerospike nozzle design gives an indication of the relative importance of an MDO design process. The convergence of the GLOW is shown on Fig. 9. Greater than 4 percent improvement, the " $\triangle \mathrm{MDO}$," in the objective function was obtained with the MDO approach. This improvement was obtained by decreasing the thrust (Fig. 10) slightly, approximately 0.1 percent, which resulted in a reduction in nozzle weight.

The final results for each case and the initial value of the objectives and the design parameters are given in Table 3 and Table 4, respectively. Note that significant changes in the design variables are observed between the single-discipline optimized solution and the MDO with eight variables that vary by more than 5 percent.

\section{Summary}

A multidisciplinary analysis of an aerospike nozzle has been developed both for evaluating multidisciplinary optimization strategies and new preliminary design processes. Thrust and nozzle wall pressure calculations were made using computational fluid dynamics and were linked to a structural finite-element analysis for determining nozzle weight and structural integrity. A mission-average specific impulse and engine thrust-toweight ratio were calculated and used to determine vehicle gross liftoff weight (utilizing data defined during the vehicle conceptual design).

The multidisciplinary analysis was integrated with an optimization code that allowed investigation of the multidisciplinary feasible strategy. A multidisciplinary design was computed, and was compared with a design that resulted from optimizing each discipline sequentially. The MDO design resulted in an improvement in the gross liftoff weight of greater than 4 percent over the singlediscipline optimized solution. The improvement was obtained by reducing the nozzle thrust, which resulted in a lower pressure loading on the nozzle structure and a lower nozzle weight. The advantages of the MDO approach were demonstrated by the improvement in the design objective and the ease of including multidisciplinary design variables in the design process.

In the future, our plans are to concentrate in two areas. We are interested in improving the physical model of the aerospike nozzle (by including additional disciplines and additional trajectory points in the multidisciplinary analysis), and we also plan to investigate approximation methods and their use in MDO problems.

\section{Acknowledgment}

The authors would like to acknowledge the contributions of both Mr. Chris Brown of Rocketdyne, Division of Boeing North American, for developing the base-pressure algorithm, and Mr. John D. Elvin of Lockheed Martin Skunk Works for providing the gross liftoff weight data. 


\section{References}

'Sweetman, B., "VentureStar: 21st Century Space Shuttle," Popular Science, Oct. 1996, pp. 42-47.

${ }^{2}$ Sobieski, J., "Multidisciplinary Design Optimization: Attempt at Definition," Proceedings of IndustryUniversity Workshop on Multidisciplinary Aircraft Design, Virginia Polytechnic Institue and State Univ., 1993, pp. 23-48.

${ }^{3}$ Cramer, E. J., Dennis, J.E. Jr., Frank, P. D., Lewis, R. M., and Shubin, G. R., "Problem Formulation for Multidisciplinary Optimization," SIAM J. Optimization, Vol. 4, No. 4, Nov. 1994, pp. 754-776.

${ }^{4}$ Rao, G. V. R., "Recent Developments in Rocket Nozzle Configurations," ARS Journal, Sept. 1961, pp. 14881494.

${ }^{5}$ Mueller, T.J., and Sule, W.P.,"Basic Flow Characteristics of a Linear Aerospike Nozzle Segment," ASME Paper 72-WA/Aero-2, Nov. 1972.

${ }^{6}$ Rommel, T., Hagemann, G., Schley, C., Krülle, G., and Manski, D., "Plug Nozzle Flowfield Calculations for SSTO Applications," AIAA Paper 95-2784, July 1995.

${ }^{7}$ Hagemann, G., Schley, C. A., Odintsov, E., and Sobatchkine, A., "Nozzle Flowfield Analysis With Particular Regard to 3D-Plug-Cluster Configurations," AIAA Paper 96-2954, July 1996.

${ }^{8}$ Iacobellis, S. F., Larson, V. R., and Burry, R. V., "Liquid-Propellant Rocket Engines: Their Status and Future," J. of Spacecraft and Rockets, Vol. 4, Dec. 1967, pg. 1569-1580.

${ }^{9}$ Angelino, G., "On the Performance of Plug-Type Nozzles," L'Aerotecnica, Vol. 43, Jun. 1963, pp.101110.

${ }^{10}$ Rommel, T., Hagemann, G., Schley, C., Krulle, G., and Manski, D., "Plug Nozzle Flowfield Calculations for SSTO Applications," AIAA Paper 95-2784, July 1995.

${ }^{11}$ Baumgartner, R. I. and Elvin, J. D., "Lifting Body-An Innovative RLV Concept," AIAA Paper 95-3531, Sept. 1995.

${ }^{12}$ Morel, R., Dalbies, E., Le Fur, Th., Schoeyer, H. F. R., Hufenbach, B., Immich, $H$. and Boman, A., "The Clustered Bell Aerospike Engine: Potential, Limitations and Preparation for Experimental Validation," IAF-95S.2.04, Oct. 1995.

${ }^{13}$ Immich, H., and Caporicci, M., "FESTIP Technology Developments in Liquid Rocket Propulsion for Reusable Launch Vehicles," AIAA Paper 96-3113, July 1996.

${ }^{14}$ Greer, H., "Rapid Method for Plug Nozzle Design", ARS Journal, April 1961, pp. 560-561.

${ }^{15}$ Angelino, G., "Approximate Method for Plug Nozzle Design," AIAA Journal Vol. 2, No.10, Oct. 1964, pp. 1834-1835.

${ }^{16}$ Rao, G. V. R., "Spike Nozzle Contour for Optimum Thrust," Ballistic Missile and Space Technology, Vol. 2, (Morrow, C. W., ed.), Pergamon Press, New York, 1961, pp. 92-101.

${ }^{17}$ Lee, C.C., and Thompson, D.D., "Computation of Plug Nozzle Contours by the Rao Optimum Thrust Method." NASA TM X-53078, 1964.
${ }^{18}$ Humphreys, R. P., Thompson, H. D., and Hoffmann, J. D., "Design of Maximum Thrust Plug Nozzles for Fixed Inlet Geometry," AIAA Journal, Vol. 9, Aug. 1971, pp. 1581-1587.

${ }^{19}$ Follett, W. W., Ketchum, A. C., and Hsu, Y. F., "Optimization Methodology for Design of ThreeDimensional Rocket Nozzles," ASME Proceedings FED232, Nov. 1995, pg. 87.

${ }^{20}$ Korte, J. J., "An Explicit Upwind Algorithm for Solving the Parabolized Navier-Stokes Equations," NASA TP-3050, Feb. 1991.

${ }^{21}$ Chapman, D. R., Kuehn, D. M., and Larson, H. K. "Investigation of Separated Flows in Supersonic and Subsonic Streams with Emphasis on the Effect of Transition," NACA TR-1356, 1958.

${ }^{22}$ Korst, H. H., Page, R. H., and Childs, M. E., "A Theory for Base Pressures in Transonic and Supersonic Flow," TN392-2, Mechanical Engineering Department, University of Illinois, March 1955.

${ }^{23}$ ANSYS Users Manual for Revision 5.0, Swanson Analysis Systems, Inc., Houston, PA, 1992.

${ }^{24}$ Moore, G. J., "MSC/NASTRAN Design Sensitivity and Optimization User's Guide," The MacNeal Schwendler Corp., April 1992.

${ }^{25}$ MATLAB Reference Guide, The MathWorks, Inc., August 1992.

${ }^{26}$ Braun, R. D., "Collaborative Optimization: An Architecture for Large-Scale Distributed Design," Ph.D. Thesis, Dept. of Astronautics and Aeronautics, Stanford Univ., May 1996.

${ }^{27}$ Vanderplaats, G. N., "CONMIN-A Fortran Program for Constrained Function Minimization User's Manual," NASA TM X-62282, August 1973. 
Table 1. Design Variables

\begin{tabular}{|c|c|c|c|}
\hline$\# \#$ & Type & Description & Initial Value \\
\hline 1 & Geo. & Thruster angle & --- \\
\hline 2 & “ & Base height & $-\cdots$ \\
\hline 3 & “ & Nozzle wall slope $\left(\mathrm{x}=10^{\prime \prime}\right)$ & $-\cdots$ \\
\hline 4 & “ & Nozzle wall slope (exit) & --- \\
\hline 5 & Stru. & Box depth & $7.00 \mathrm{in}$. \\
\hline 6 & “ & Outer (hot) wall thickness & 0.0260 in. \\
\hline 7 & " & Inner (cold) wall thickness & $0.0267 \mathrm{in}$. \\
\hline 8 & “ & Truss Outer radius $(1-6)$ & $0.6039 \mathrm{in}$. \\
\hline 9 & “ & Truss Tube thickness $(1-6)$ & $0.2864 \mathrm{in}$. \\
\hline 10 & “ & I-beam column width & $1.521 \mathrm{in.}$ \\
\hline 11 & “ & I-beam flange width & 0.1935 in. \\
\hline 12 & “ & I-beam flange height (1-10) & $0.0711 \mathrm{in}$. \\
\hline 13 & 4 & I-beam column ht. $(1-10)$ & 0.0506 in. \\
\hline 14 & “ & Axial web thickness & 0.0242 in. \\
\hline 15 & “ & \begin{tabular}{|l} 
Longitudinal web thickness \\
\end{tabular} & 0.0050 in. \\
\hline 16 & “ & Radius of shell stiffener & 0.2011 in. \\
\hline 17 & “ & Thickness of shell stiffener & $0.0298 \mathrm{in}$. \\
\hline 18 & $" 6$ & Thickness of base plate & 0.1665 in. \\
\hline
\end{tabular}

Table 2. Structural Parameters

\begin{tabular}{l|l}
\hline \multicolumn{1}{c|}{ Parameter Name } & \multicolumn{1}{c}{ Value } \\
\hline Hot wall yield stress & $16,000 \mathrm{psi}$ \\
\hline Yield stress except for hot wall & $120,000 \mathrm{psi}$ \\
\hline Safety factor for shell and supports & 1.5 \\
\hline Safety factor for buckling & 3.0 \\
\hline Maximum vert. displacement of nozzle & $0.25 \mathrm{in}$. \\
\hline
\end{tabular}

Table 3. Design Variable Results

\begin{tabular}{|c|c|c|c|}
\hline $\begin{array}{c}\text { Design } \\
\text { Variable } \\
\text { Number* }\end{array}$ & $\begin{array}{l}\text { Initial } \\
\text { Value }\end{array}$ & $\begin{array}{l}\text { Method I } \\
\text { Single } \\
\text { Discipline }\end{array}$ & $\begin{array}{c}\text { Method II } \\
\text { MDO }\end{array}$ \\
\hline 1 & 1.15 & 1.00 & 0.970 \\
\hline 2 & 0.908 & " & 0.823 \\
\hline 3 & 1.01 & $"$ & 1.03 \\
\hline 4 & 1.17 & “" & 1.01 \\
\hline 5 & 0.773 & “" & 0.957 \\
\hline 6 & 1.14 & 6 & 0.912 \\
\hline 7 & 1.16 & $"$ & 0.917 \\
\hline 8 & 1.03 & 6 & 0.985 \\
\hline 9 & 1.08 & “ & 0.957 \\
\hline 10 & 1.08 & 16 & 0.950 \\
\hline 11 & 1.00 & $"$ & 0.997 \\
\hline 12 & 1.09 & $"$ & 0.951 \\
\hline 13 & 1.00 & $"$ & 0.998 \\
\hline 14 & 1.31 & $" 6$ & 0.827 \\
\hline 15 & 0.847 & $" “$ & 0.983 \\
\hline 16 & 1.09 & “ & 0.947 \\
\hline 17 & 1.08 & “ & 0.957 \\
\hline 18 & 0.950 & $" “$ & 0.932 \\
\hline
\end{tabular}

Table 4. Design Objective Function Results

\begin{tabular}{l|c|c|c}
\hline Objective & $\begin{array}{c}\text { Initial } \\
\text { Value }\end{array}$ & $\begin{array}{c}\text { Method I } \\
\text { Single } \\
\text { Discipline }\end{array}$ & $\begin{array}{c}\text { Method II } \\
\text { MDO }\end{array}$ \\
\hline Total thrust* & 0.999 & 1.000 & 0.999 \\
\hline Nozzle wt. $^{*}$ & 1.250 & 1.000 & 0.813 \\
\hline GLOW* $^{*}$ & $>3.0^{* *}$ & 1.000 & 0.957 \\
\hline
\end{tabular}

*Nondimensionalized by optimized design for each discipline (Method I).

**Outside bounds of routine.

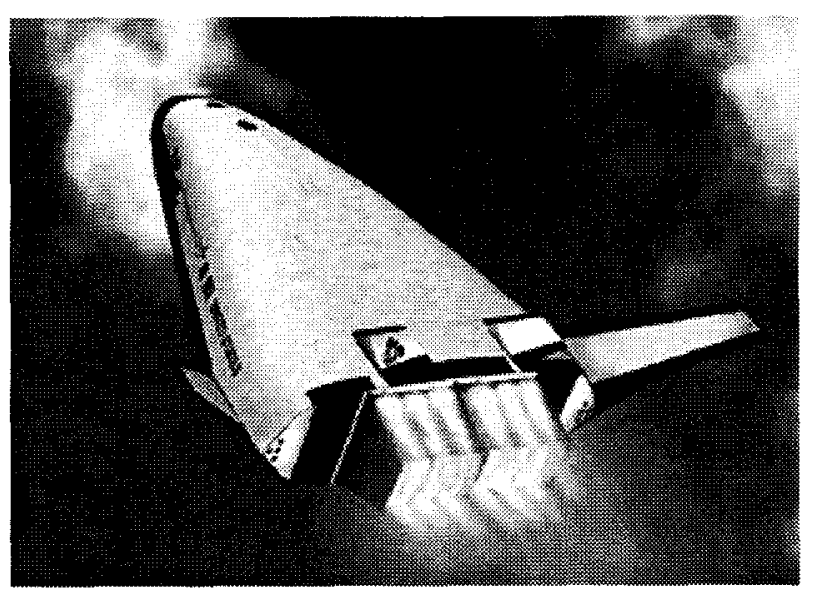

Fig. 1 VentureStar reusable launch vehicle with linear aerospike propulsion system.

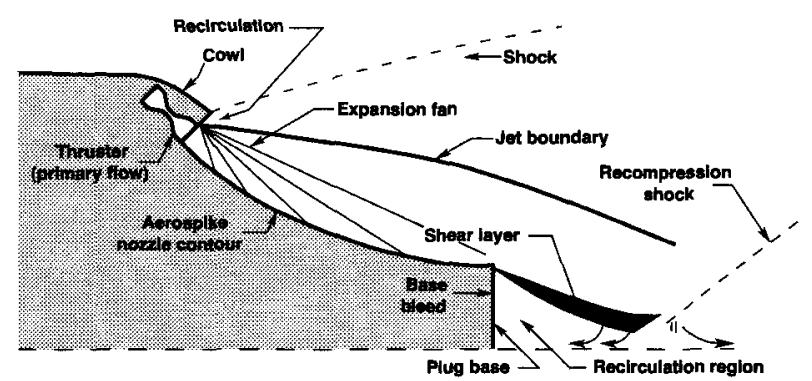

Fig. 2 Aerospike components and flow-field characteristics.

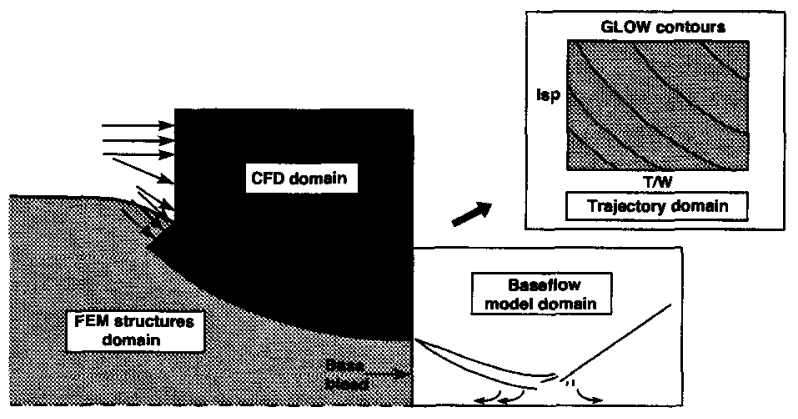

Fig. 3 Multidisciplinary domain decomposition. 


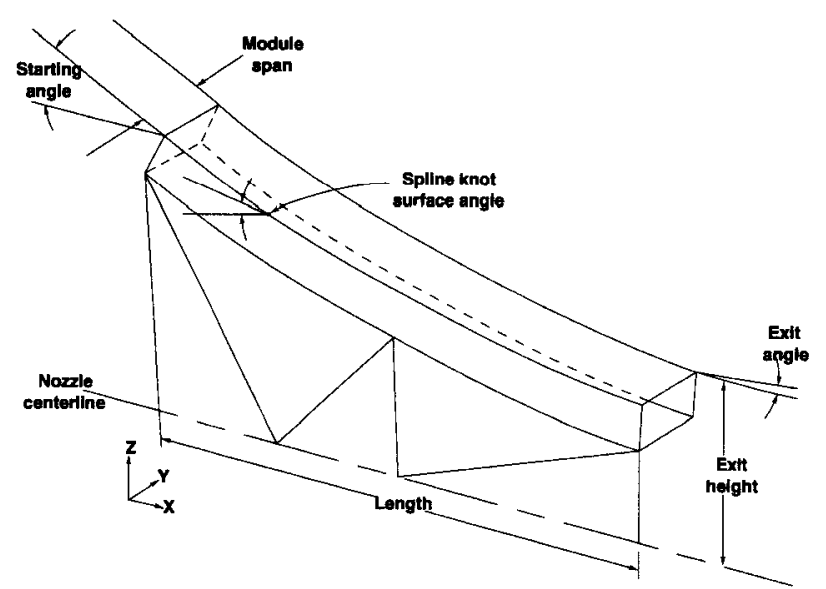

Fig. 4 Aerospike nozzle geometry design parameters.

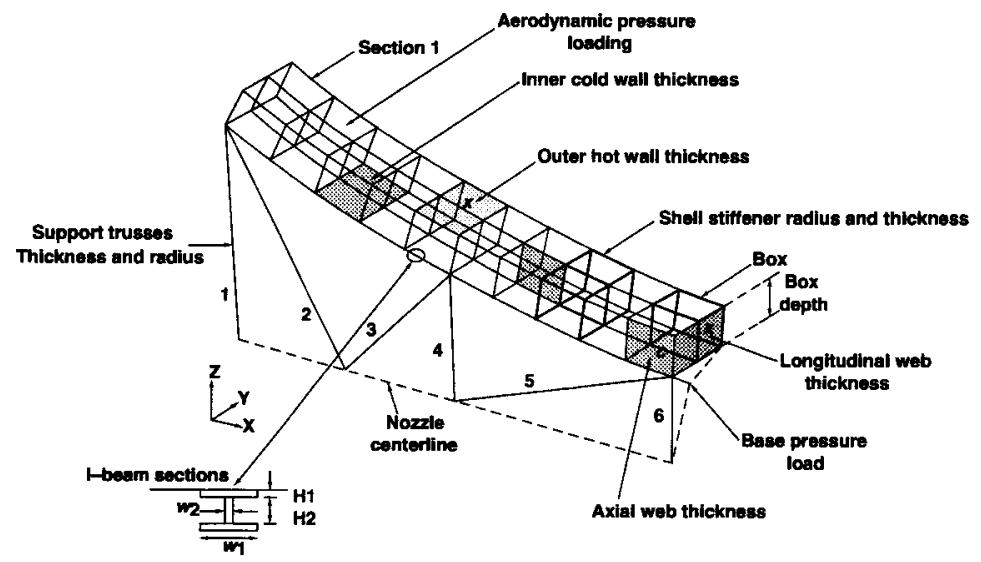

Fig. 5 Aerospike nozzle structural design parameters.

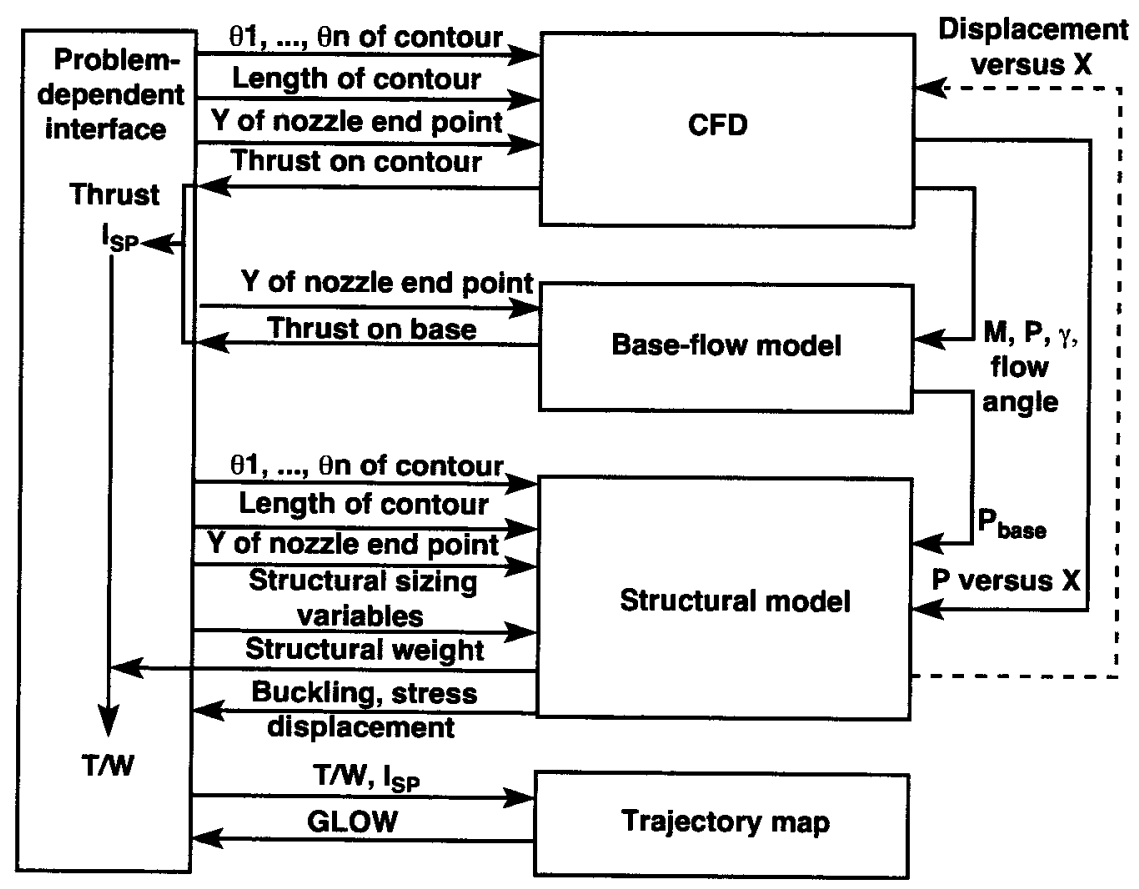

Minimize GLOW S.T. constraints

- Includes: Hot wall thickness, tube diameters, tube wall thickness, I-beam web thickness, etc.

Fig. 6 Multidisciplinary aerospike nozzle analysis. 


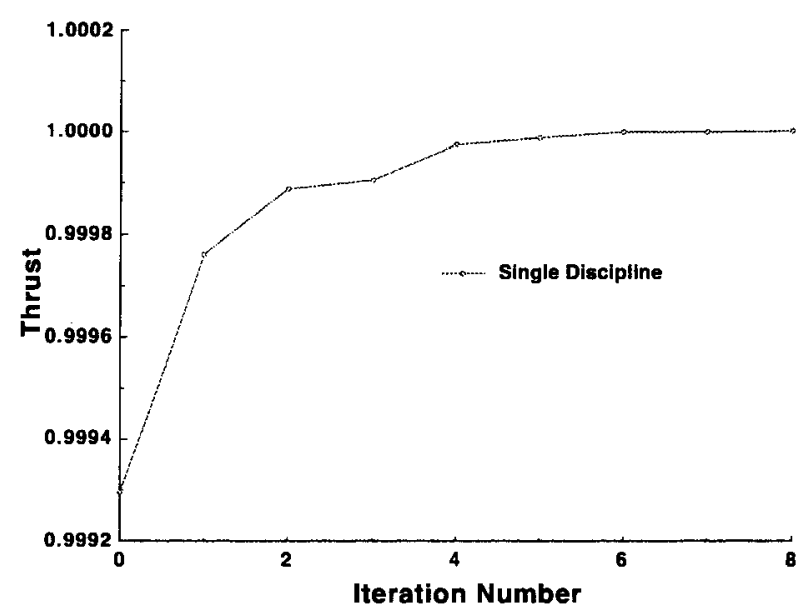

Fig. 7 Convergence of aerospike engine thrust for Method I.

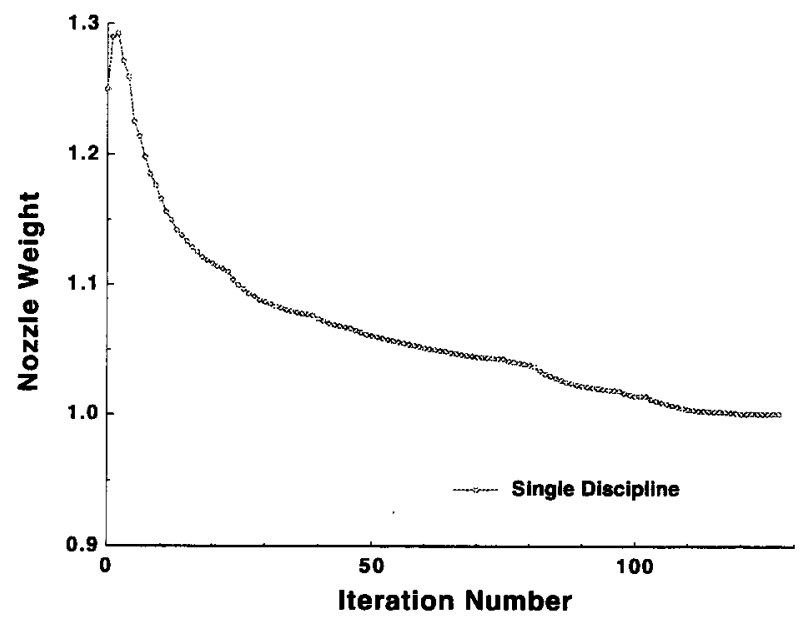

Fig. 8 Convergence of nozzle weight for Method I.

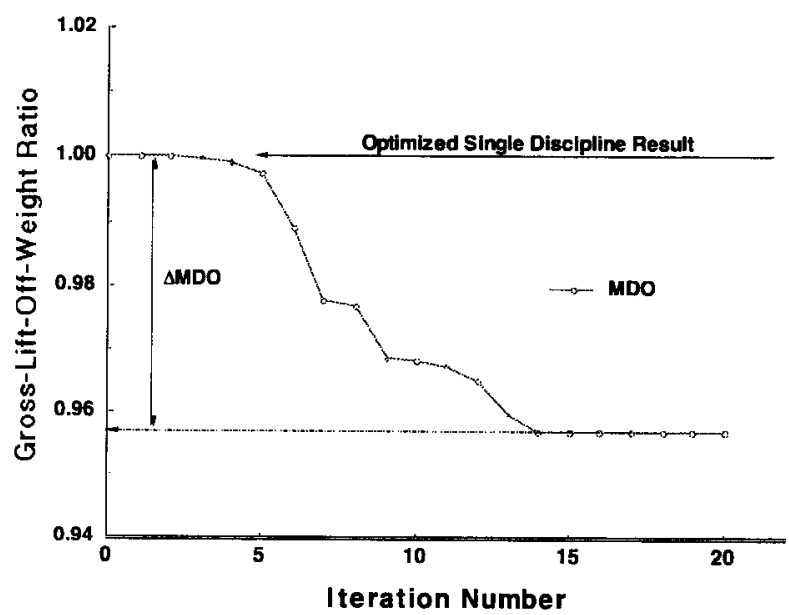

Fig. 9 Convergence of MDO objective function, Method II.

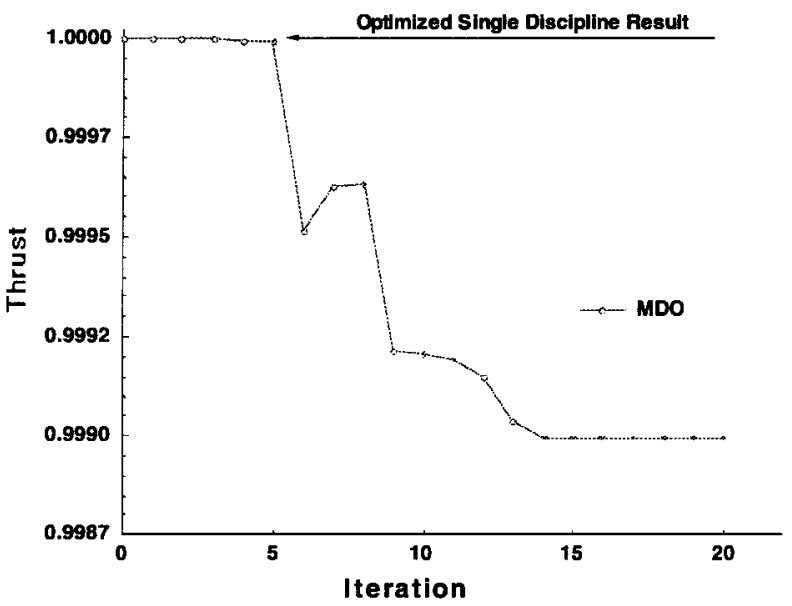

Fig. 10 Convergence of aerospike engine thrust, Method II. 